\title{
EFEKTIFITAS PENGGUNAAN MEDIA ANIMASI UNTUK MENINGKATKAN PENGETAHUAN TENTANG HIV/AIDS
}

\author{
Sovia $^{* 1}$, Suharti ${ }^{2}$, Daryono ${ }^{3}$ \\ ${ }^{1.2}$ Jurusan Keperawatan, Poltekkes Kemenkes Jambi \\ e-mail: soviadamhur@gmail.com
}

\begin{abstract}
Abstrak
Terjadinya peningkatan jumlah penderita HIV/AIDS setiap tahunnya.Di Propinsi Jambi, dari tahun 1999 hingga Desember 2016, tercatat ada 1.537 orang penderita HIV/ AIDS, 80\% penderita HIV/AIDS berasal dari Kota Jambi, dan 32\% penderita termasuk kelompok umur dewasa muda dan remaja. Penelitian ini bertujuan untuk mengetahui efektifitas penggunaan media animasi terhadap peningkatan pengetahuan remaja tentang penyakit HIV/AIDS. Jenis penelitian eksperimen semu (Quasi Eksperimen). Pengumpulan data dilaksanakan di SMK Dharma Bhakti (DB) 1 Kota Jambi. Populasi penelitian adalah seluruh siswa/i yang berjumlah 257 orang, dengan sampel sebanyak 142 orang yang diambil secara stratified random sampling. Pengumpulan data menggunakan kuisioner yang dilakukan sebanyak 2 kali, yaitu: pretest dan posttest. Analisis data menggunakan Uji T kelompok tidak berpasangan.

Hasil: Rerata pengetahuan responden pada kelompok media powerpoint adalah 52,55 dan rerata pengetahuan responden pada kelompok media animasi adalah 55,40.Terdapat perbedaan rerata antara pengetahuan responden yang diberikan pendidikan kesehatan dengan menggunakan media powerpoint dan menggunakan media animasi(p-value 0,005 dan $\alpha$ 0,05). Simpulan: Penggunaan media animasi lebih efektif daripada media powerpoint dalam pemberian informasi tentang penyakit HIV/AIDS pada remaja. Diharapkan media animasi ini dapat digunakan dalam melakukan pendidikan kesehatan pada remaja tentang HIV/AIDS secara rutin.
\end{abstract}

Kata Kunci : HIV/AIDS; Media animasi; remaja

\begin{abstract}
There is an increase in the number of people with HIV / AIDS every year. In Jambi Province, from 1999 to December 2016, there were 1,537 people with HIV / AIDS, 80\% of HIV / AIDS patients from Jambi City, and 32\% of young people included and teenagers. This study aims to determine the effectiveness of the use of animation media to increase adolescent knowledge about HIV / AIDS. Type of quasi-experimental research (Quasi Experiment). Data collection was carried out at SMK Dharma Bhakti (DB) 1 Jambi City. The study population was all students taken 257 people, with a sample of 142 people taken randomly stratified sampling. Data collection using questionnaires carried out 2 times, namely: pretest and posttest. Data analysis using unpaired group T test.

Results: The mean knowledge of respondents in the powerpoint media group was 52.55 and the average knowledge of respondents in the animation media group was 55.40. There was a difference in the average knowledge of respondents given health education using powerpoint media and using media animation (p-value 0.005 and $\alpha$ 0.05). Conclusion: Using animation media is more effective than powerpoint media in providing information about HIV / AIDS in adolescents. It is hoped that this animation media can be used in conducting health education for adolescents on HIV / AIDS regularly.
\end{abstract}

Keywords: Animation Media; HIV / AIDS;Teenagers

(C) 2019- Sovia, Suharti, Daryono Under the license CC BY-SA 4.0 


\section{PENDAHULUAN}

HIV adalah virus yang menyerang sistem kekebalan tubuh manusia sehingga melemahkan kemampuan tubuh untuk melawan penyakit. AIDS merupakan kumpulan gejala penyakit akibat lemahnya sistem kekebalan tubuh (Murni, 2011).

Jumlah penyakit HIV/ AIDS terus mengalami peningkatan dari tahun ke tahun. Pada tahun 2013, di seluruh dunia terdapat 35 juta orang yang hidup dengan HIV dan 3,2 juta anak berusia $<15$ tahun. Jumlah infeksi baru HIV sebesar 2,1 juta yang terdiri dari 1,9 juta dewasa dan 240.000 anak berusia $<15$ tahun (Pusat Data dan Informasi Kemenkes RI, 2014). Pada tahun 2015 dilaporkan sebanyak 36,7 juta orang di dunia yang hidup dengan HIV/ AIDS, dan sebanyak 25,5 juta orang berada di Afrika (Harahap, 2017). Kasus infeksi baru di dunia ditemukan sebanyak 1,8 juta jiwa pada tahun 2016 (Rahman, 2017). Jumlah kematian akibat AIDS sebanyak 1,5 juta yang terdiri dari 1,3 juta dewasa dan 190.000 anak berusia < 15 tahun pada tahun 2013 (Pusat Data dan Informasi Kemenkes RI, 2014).

Laporan Ditjen P2P Kemenkes RI pada tanggal 24 Mei 2017, menunjukkan jumlah kasus kumulatif HIV/ AIDS secara nasional sejak tahun 1987 sampai dengan Maret 2017 berjumlah 330.152 yang terdiri atas 242.699

HIV dan 87.453 AIDS dengan 14,754 kematian (Harahap, 2017). Sedangkan di Propinsi Jambi, dari tahun 1999 hingga Desember 2016, tercatat ada 1.537 orang penderita HIV/ AIDS dan $80 \%$ penderita HIV/ AIDS berasal dari Kota Jambi (Nurlailis, 2017). Pada tahun 2014, di Propinsi Jambi jumlah kasus HIV sebanyak 751 orang dan kasus AIDS sebanyak 458 orang, serta prevalensi sebesar $14.81 \%$ (Ditjen PP \& PL Kemenkes RI, 2014).

Jumlah kumulatif kasus HIV/AIDS menurut golongan umur di Indonesia pada tahun 2014 adalah < 1 tahun (238 orang), 1-4 tahun (968 orang), 5-14 tahun (441 orang), 1519 tahun (1.717 orang), 20-29 tahun(18.352 orang), 30-39 tahun (15.890 orang), 40-49 tahun (5.974 orang), 50-59 tahun (1.874 orang), dan $\geq 60$ tahun (551 orang), dan tidak diketahui (9.794 orang) (Ditjen PP \& PL Kemenkes RI, 2014). Menurut Direktur Pengendalian Penyakit Menular Kementerian Kesehatan RI, sampai September 2015 didapatkan kasus HIV/ AIDS tertinggi pada usia 20-29 tahun (32\%), 30-39 tahun (29,4\%), 40-49 tahun (11,8\%), 50-59 tahun (3,9\%), dan terakhir usia 15-19 tahun (3\%) (Iradat, 2015).

Menurut data diatas, kasus HIV/ AIDS yang tertinggi dalam tahun 2014 dan 2015 berada pada rentang usia 20-29 tahun (usia dewasa muda). Hal ini menunjukkan bahwa penderita HIV/ AIDS kemungkinan sudah terkontaminasi dengan HIV sejak mereka masih berusia remaja (12-20 tahun) karena masa inkubasi dari HIV menjadi AIDS membutuhkan waktu beberapa tahun. Nursalam dan Kurniawati (2007) menuliskan bahwa seseorang yang terinfeksi HIV akan menunjukkan tanda dan gejala AIDS setelah 19 tahun yang akan datang.

Stanhope dan Lancaster (2004), Allender dan Spraddley (2001), Allender, Rector, dan Warner (2010), mengatakan bahwa penyakit menular seksual dan HIV/ AIDS merupakan salah satu dari masalah-masalah kesehatan yang terjadi pada remaja. United Nations Programme on HIV/AIDS (UNAIDS) melaporkan, terdapat lebih dari 2 juta infeksi baru selama 2015, yang 150.000 di antaranya terjadi pada usia di bawah 15 tahun. Selain itu, UNAIDS mencatat ada 1,1 juta jiwa meninggal dunia karena penyakit terkait AIDS pada 2015 dan 110.000 di antaranya merupakan anakanak dibawah 15 tahun (Gareta, 2016).

Penularan HIV/ AIDS dapat terjadi pada remaja melalui hubungan seksual secara bebas yang dilakukan remaja ataupun melalui penggunaan jarum suntik yang tidak steril karena penyalahgunaan narkoba. Kemenkes RI (2016) menyatakan bahwa faktor risiko penularan HIV tertinggi adalah hubungan seks tidak aman pada heteroseksual (66\%), penggunaan jarum suntik tidak steril pada penasun (pengguna narkoba suntik) (11,3\%), homoseksual $(2,9 \%)$ dan penularan melalui perinatal $(2,8 \%)$. Penularan HIV/ AIDS pada remaja ini tentunya akan menambah jumlah 
kasus HIV/ AIDS setiap tahunnya. Di Propinsi Jambi, penyebab penularan HIV/ AIDS adalah heteroseksual (44,6\%), IDU (44,2\%), homoseksual (4\%), biseksual $(4,5 \%)$, perinatal $(2,2 \%)$, dan tidak diketahui $(0,4 \%)$ (Nurlailis, 2017).

Peningkatan kasus HIV/ AIDS setiap tahun akan berdampak terhadap terjadinya peningkatan angka kesakitan dan kematian, serta mempunyai dampak pada masalah psikologi dan sosial. Oleh sebab itu, dibutuhkan upaya promotif dan preventif untuk memperkenalkan kepada masyarakat luas, khususnya pada kelompok usia remaja tentang bahaya, pencegahan, dan penanggulangan penyakit HIV/AIDS.

Hal ini sejalan dengan sasaran pokok RPJMN 2015-2019, diantaranya adalah meningkatnya pengendalian terhadap penyakit (Kemenkes RI, 2016). Salah satu pengendalian penyakit yang menjadi prioritas adalah penyakit menular, seperti: HIV/AIDS, TB Paru, dan Malaria. Hal ini sejalan dengan pencapaian program SDGs (Sustainable Development Goals) pada tahun 2030, dimana salah satu tujuannya adalah berakhirnya epidemik dari penyakit menular, seperti: AIDS, tuberkulosis, malaria, penyakit tropis terabaikan, hepatitis, dan lain-lain (General Asembly, 2015)

Salah satu cara yang dapat dilakukan adalah dengan menggalakkan pendidikan kesehatan pada masyarakat, khususnya kelompok remaja. Selama ini, pendidikan kesehatan pada remaja tentang dampak (bahaya) HIV/ AIDS dan pencegahannya masih dirasakan kurang optimal. Selain itu, sulitnya menyampaikan sesuatu yang bersifat abstrak dan kompleks pada remaja. Oleh karena itu dibutuhkan metode dan media yang tepat untuk digunakan dalam penyampaian materi tersebut pada remaja.

Media yang dapat digunakan dalam pendidikan kesehatan dapat bermacam-macam, antara lain: media visual, media audio, media audio visual, dan multimedia (Asyhar, 2012). Menurut Rusman, Kurniawan, dan Riyana (2013), multimedia dapat berupa film, animasi, powerpoint, dan lain-lain.
Penelitian tentang media animasi pernah dilakukan oleh Andriany (2016), dengan judul "Perbandingan efektifitas media penyuluhan poster dan kartun animasi terhadap pengetahuan kesehatan gigi dan mulut pada siswa kelas V SDN 24 Kota Banda Aceh". Hasil penelitian menunjukkan bahwa media penyuluhan kartun animasi lebih efektif dibandingkan media poster dalam meningkatkan pengetahuan kesehatan gigi danmulut pada siswa kelas V SDN 24 Kota Banda Aceh.

Penyampaian informasi tentang HIV/ AIDS kepada siswa/i di sekolah yang dilakukan selama ini lebih banyak menggunakan media gambar, leaflet, majalah, buku pelajaran, dan poster. Media yang monoton dan membosankan akan menyebabkan kurangnya perhatian siswa/i terhadap pesan yang akan disampaikan. Apabila kondisi ini dibiarkan maka mengakibatkan remaja tidak memahami bahaya HIV/AIDS dan pada akhirnya remaja akan menunjukkan perilaku berisiko untuk tertular penyakit HIV/AIDS.

Berdasarkan uraian diatas, maka perlu dilakukan penelitian terkait penggunaan media pembelajaran yang variatif dalam memberikan pendidikan kesehatan pada remaja tentang penyakit HIV/ AIDS.

\section{METODE PENELITIAN}

Jenis penelitian eksperimen semu (Quasi Eksperimen) dengan teknik intervensi dan observasi yang bertujuan untuk mengetahui efektifitas penggunaan media animasi terhadap peningkatan pengetahuan remaja tentang penyakit HIV/AIDS. Pengumpulan data dilakukan di SMK DB 1 Kota Jambi pada tanggal 9-21 Oktober 2017.Populasipenelitian adalah seluruh siswa/i yang berjumlah 257 orangdengan sampel sebanyak 110 orang yang diambil secara stratified random sampling. Sampel dibagi dua kelompok, yaitu: kelompok media powerpoint sebanyak 55 orang dan kelompok media animasi sebanyak 55 orang.Kuisioner penelitian diadopsi dan dimodifikasi dari kuisioner penelitian Saputra (2008). Kuisioner 
terdiri dari 35 pertanyaan pilihan ganda dan cheklist tentang HIV/ AIDS. Media pendidikan kesehatan yang digunakan berupa video animasi tentang "Aku Bangga Aku Tahu: Penyakit HIV/AIDS" yang diadopsi dari Kementerian Kesehatan Republik Indonesia.Pengumpulan data dilakukan dua kali, yaitu: pretest dan posttest.Analisis data menggunakan Uji $\mathrm{T}$ kelompok tidak berpasangan (untuk melihat perbedaan rerata kedua kelompok sampel).

\section{HASIL DAN PEMBAHASAN}

\subsection{Hasil Penelitian}

Karakteristik responden dalam penelitian ini, yaitu: umur, jenis kelamin, dan kelas. Untuk pemilihan responden antara kelompok media powerpoint dan media animasi, peneliti hanya melihat dari kesesuaian jenis kelamin.

Tabel 1 Distribusi Frekuensi Responden Berdasarkan Umur Siswa/i SMK DB 1Kota Jambi Tahun 2017

\begin{tabular}{ccccc}
\hline \multirow{2}{*}{ Umur } & \multicolumn{2}{c}{ Kelompok } & \multicolumn{2}{c}{ Kelompok Animasi } \\
\cline { 2 - 5 } & $\mathbf{f}$ & $\mathbf{\%}$ & $\mathbf{F}$ & \% \\
\hline 14 tahun & 2 & 3,6 & 3 & 5,4 \\
\hline 15 tahun & 16 & 29,1 & 18 & 32,7 \\
\hline 16 tahun & 20 & 36,4 & 20 & 36,4 \\
\hline 17 tahun & 15 & 27,3 & 10 & 18,2 \\
\hline 18 tahun & 2 & 3,6 & 4 & 7,3 \\
\hline Total & 55 & 100 & 55 & 100 \\
\hline
\end{tabular}

Sumber : Data Primer

Tabel diatas menunjukkan bahwa responden terbanyak berada pada usia 16 tahun $(36,4 \%)$, baik pada kelompok media powerpoint ataupun kelompok media animasi. Sedangkan paling kecil usia responden berada pada usia 14 tahun dan 18 tahun $(3,6 \%)$ untuk kelompok media powerpoint dan usia 14 tahun $(5,4 \%)$ pada kelompok media animasi.

Tabel 2 Distribusi Frekuensi Responden Berdasarkan Jenis Kelamin Siswa/i SMK DB 1

Kota Jambi Tahun 2017

\begin{tabular}{llclc}
\multirow{2}{*}{$\begin{array}{c}\text { Jenis } \\
\text { Kelamin }\end{array}$} & \multicolumn{2}{c}{ Kelompok } & \multicolumn{2}{c}{ Kelompok } \\
& \multicolumn{2}{c}{ Powerpoint } & \multicolumn{2}{c}{ Animasi } \\
\cline { 2 - 5 } & $\mathbf{f}$ & $\%$ & F & $\%$ \\
\hline Lak1-lak1 & 35 & 63,6 & 35 & 63,6 \\
\hline Perempuan & 20 & 36,4 & 20 & 36,4 \\
\hline Total & 55 & 100 & 55 & 100 \\
\hline
\end{tabular}

Sumber : Data Primer
Berdasarkan tabel 2 dapat diketahui bahwa responden terbanyak memiliki jenis kelamin laki-laki $(63,6 \%)$, baik pada kelompok media powerpoint ataupun kelompok media animasi.

Tabel 3 Distribusi Frekuensi Responden Berdasarkan Kelas Siswa/i SMK DB 1 Kota Jambi Tahun 2017

\begin{tabular}{lcccc}
\hline \multirow{2}{*}{ Kelas } & \multicolumn{2}{c}{$\begin{array}{c}\text { Kelompok } \\
\text { Powerpoint }\end{array}$} & \multicolumn{2}{c}{$\begin{array}{c}\text { Kelompok } \\
\text { Animasi }\end{array}$} \\
\cline { 2 - 5 } & f & \% & F & \% \\
\hline X & 29 & 52,7 & 24 & 43,6 \\
\hline XI & 16 & 29,1 & 25 & 45,5 \\
\hline XII & 10 & 18,2 & 6 & 10,9 \\
\hline Total & 55 & 100 & 55 & 100 \\
\hline
\end{tabular}

Sumber : Data Primer

Pada tabel 3 diatas dapat terlihat bahwa paling banyak responden berasal dari kelas $\mathrm{X}$ pada kelompok media powerpoint $(52,7 \%)$ dan kelas XI pada kelompok media animasi $(45,5 \%)$. Sedangkan sejumlah kecil responden sedang duduk di kelas XII, yaitu sebesar 18,2\% untuk kelompok powerpoint dan 10,9\% untuk kelompok media animasi.

Pengetahuan siswa/i yang diberikan pendidikan kesehatan tentang penyakit HIV/AIDSdengan menggunakan media powerpointdikelompokkan menjadi dua kategori dengan menggunakan cut of point nilai mean (52,09 untuk pre-test dan 52,55 untuk post-test).

Tabel 4 Distribusi Frekuensi Tingkat Pengetahuan Responden Menggunakan Media Powerpoint Pada Siswa/i SMK DB 1 Kota Jambi Tahun 2017

$\begin{array}{llll}\text { No. } & \begin{array}{c}\text { Tingkat } \\ \text { Pengetahuan }\end{array} & \text { f } & \%\end{array}$

\begin{tabular}{llll} 
1. & Pre-test & & \\
\cline { 2 - 3 } a. Tinggi & 23 & 41,8 \\
\hline b. Rendah & 32 & 58,2 \\
\cline { 2 - 3 } & Total & 55 & 100 \\
\hline 2. & Post-test & & \\
\cline { 2 - 3 } a. I Inggı & 54 & $01, \mathrm{o}$ \\
\hline & b. Rendah & 21 & 38,2 \\
\hline Total & 55 & 100 \\
\hline
\end{tabular}

Sumber : Data Primer 
Tabel 4 menunjukkan bahwa sebelum diberikan pendidikan kesehatan, siswa/i yang memiliki tingkat pengetahuan rendah lebih banyak dibandingkan dengan siswa/i yang memiliki tingkat pengetahuan tinggi. Sedangkan setelah diberikan pendidikan kesehatan, siswa/i yang mempunyai tingkat pengetahuan tinggi lebih banyak dibandingkan tingkat pengetahuan rendah.

Tabel 5 Perbedaan Rerata Pengetahuan

Responden Sebelum dan Setelah Diberikan

Pendidikan Kesehatan Menggunakan Media

Powerpoint Pada Siswa/i SMK DB 1 Kota

Jambi Tahun 2017

\begin{tabular}{|l|c|c|c|c|c|}
\hline $\begin{array}{c}\text { Pengetahua } \\
\mathbf{n}\end{array}$ & $\begin{array}{c}\text { Mea } \\
\mathbf{n}\end{array}$ & SD & SE & $\begin{array}{c}\boldsymbol{p} \text { - } \\
\boldsymbol{v a l u} \\
\boldsymbol{e}\end{array}$ & $\mathbf{n}$ \\
\hline Pre-test & 52,09 & 5,99 & 0,80 & 0,35 & 5 \\
& & 2 & 8 & 3 & 5 \\
\hline Post-test & 52,55 & $\begin{array}{c}4,98 \\
8\end{array}$ & $\begin{array}{c}0,67 \\
3\end{array}$ & & \\
& & 8 & & \\
\hline
\end{tabular}

Sumber : Data Primer

Tabel 5 menunjukkan bahwa rata-rata pengetahuan responden sebelum diberikan pendidikan kesehatan adalah 52,09 dengan standar deviasi 5,992. Sedangkan rata-rata pengetahuan responden setelah diberikan pendidikan kesehatan adalah 52,55 dengan standar deviasi 4,988. Terlihat perbedaan nilai mean antara sebelum dan sesudah pendidikan kesehatan sebesar 0,46 dengan standar deviasi 3,599. Hasil uji statistik didapatkan p-value 0,353 maka dapat disimpulkan bahwa tidak ada perbedaan pengetahuan responden sebelum dan sesudah diberikan pendidikan kesehatan dengan menggunakan media powerpoint.

Gambaran tingkat pengetahuan siswa/i yang diberikan pendidikan kesehatantentang penyakit HIV/AIDS dengan menggunakan media animasi, dikelompokkan menjadi dua kategori dengan menggunakan cut of point nilai mean (48,09 untuk pre-test dan 55,40 untuk post-test).

Hasil analisis menunjukkan tingkat pengetahuan siswa/i sebelum diberikan pendidikan kesehatan lebih banyak yang rendah dibandingkan yang tinggi. Sedangkan setelah diberikan pendidikan kesehatan, tingkat pengetahuan yang tinggi lebih banyak daripada tingkat pengetahuan yang rendah (lihat tabel 6).
Tabel 6 Distribusi Frekuensi Tingkat Pengetahuan Responden Menggunakan Media Animasi Pada Siswa/i SMK DB 1 Kota Jambi Tahun 2017

\begin{tabular}{|c|c|c|c|}
\hline No. & $\begin{array}{c}\text { Tingkat } \\
\text { Pengetahuan }\end{array}$ & f & $\%$ \\
\hline 1. & Pre-test & & \\
\hline & a. Tinggi & 24 & 43,6 \\
\hline & b. Rendah & 31 & 56,4 \\
\hline & Total & 55 & 100 \\
\hline 2. & Post-test & & \\
\hline & a. Tinggi & 30 & 54,5 \\
\hline & b. Rendah & 25 & 45,5 \\
\hline & Total & 55 & 100 \\
\hline
\end{tabular}

Sumber : Data Primer

Tabel 7 Perbedaan Rerata Pengetahuan Responden Sebelum dan Setelah Diberikan Pendidikan Kesehatan Menggunakan Media AnimasiPada Siswa/i SMK DB 1 Kota Jambi Tahun 2017

\begin{tabular}{lccccc}
\hline Pengetahuan & Mean & SD & SE & $\begin{array}{c}p \text { - } \\
\text { alu } \\
\boldsymbol{e}\end{array}$ & $\mathbf{n}$ \\
\hline Pre-test & 48,09 & 7,199 & 0,971 & & \\
\hline Post-test & 55,40 & 5,516 & 0,744 & &
\end{tabular}

\section{Sumber : Data Primer}

Tabel 7 memperlihatkan bahwa rata-rata pengetahuan responden sebelum diberikan pendidikan kesehatan adalah 48,09 dengan standar deviasi 7,199. Sedangkan rata-rata pengetahuan responden setelah diberikan pendidikan kesehatan adalah 55,40 dengan standar deviasi 5,516. Terlihat perbedaan nilai mean antara sebelum dan sesudah pendidikan kesehatan sebesar 7,309 dengan standar deviasi 7,146. Hasil uji statistik didapatkan p-value 0,000 maka dapat disimpulkan bahwa terdapat perbedaan yang signifikan antara pengetahuan responden sebelum dan sesudah diberikan pendidikan kesehatan dengan menggunakan media animasi.

Perbedaan nilai rerata pengetahuan responden yang mendapatkan pendidikan kesehatan dengan menggunakan media powerpoint dan media animasi dapat dilihat dengan membandingkan nilai post-test masingmasing kelompok. 
Tabel 8 Perbedaan Rerata Pengetahuan

Responden Sebelum dan Setelah Diberikan

Pendidikan Kesehatan Menggunakan Media

Powerpoint dan Media AnimasiPada Siswa/i

SMK DB 1

Kota Jambi Tahun 2017

\begin{tabular}{|c|c|c|c|c|c|}
\hline $\begin{array}{c}\text { Pengetahu } \\
\text { an }\end{array}$ & $\begin{array}{c}\text { Mea } \\
\mathbf{n}\end{array}$ & SD & SE & $\begin{array}{c}p- \\
\text { valu } \\
e\end{array}$ & $\mathbf{n}$ \\
\hline Kelompok & 52,5 & 4,98 & 0,673 & & \multirow{4}{*}{55} \\
\hline Powerpoint & 5 & 8 & & 0,00 & \\
\hline Kelompok & 55,4 & 5,51 & 0,744 & 5 & \\
\hline Animasi & 0 & 6 & & & \\
\hline
\end{tabular}

Tabel 8 memperlihatkan bahwa rata-rata pengetahuan responden yang diberikan pendidikan kesehatan menggunakan media powerpoint adalah 52,55 dengan standar deviasi 4,988. Sedangkan rata-rata pengetahuan responden yang diberikan pendidikan kesehatan dengan media animasi adalah 55,40 dengan standar deviasi 5,516. Hasil uji statistik didapatkan $p$-value 0,005 ( $\alpha$ $0,05)$, berarti ada perbedaan yang signifikan antara pengetahuan responden yang diberikan pendidikan kesehatan dengan menggunakan media powerpoint dan menggunakan media animasi. Hasil penelitian ini menunjukkan bahwa penggunaan media animasi lebih efektif daripada media powerpoint dalam pemberian informasi tentang penyakit HIV/AIDS pada siswa/i SMK DB 1 Kota Jambi Tahun 2017.

\subsection{PEMBAHASAN}

Penelitian ini mendapatkan bahwa terjadi sedikit peningkatan rerata pengetahuan siswa/i antara sebelum dan sesudah pemberian pendidikan kesehatan tentang HIV/AIDS, dengan selisih hanya 0,46 dan standar deviasi 3,599. Sehingga pada uji statistik diperoleh $p$ value 0,353 yang berarti tidak ada perbedaan pengetahuan siswa/i dari sebelum diberikan informasi tentang HIV/AIDS dengan setelah diberikan informasi dengan menggunakan media PowerPoint.

Hasil penelitian ini sejalan dengan Halimah (2014) tentang Pengaruh Media Powerpoint Terhadap Aktivitas dan Penguasaan Konsep Siswa Di SMP An-Nur Tulang Bawang Tengah Lampung. Hasil penelitian menunjukkan bahwa penggunaan media powerpoint dapat meningkatkan aktivitas belajar siswa dengan rata-rata persentase 86,63\%; akan tetapi penguasaan konsep siswa kelas eksperimen tidak berbeda signifikan dengan penguasaan konsep siswa kelas kontrol, dengan rata-rata 15,89.

Penelitian yang peneliti lakukan memiliki hasil yang berbeda dengan penelitian Maryatun (2015) dan Putri (2014). Penelitian Maryatun yang berjudul "Pengaruh Penggunaan Media Program MicrosoftPowerpoint Terhadap Hasil

Belajar Strategi Promosi Pemasaran Mahasiswa Semester 2 Program Studi Pendidikan Ekonomi Universitas Muhammadiyah Metro Tahun Ajaran 2014/2015" membuktikan bahwa rata-rata nilai pre-test pengukuran awal sebelum proses pembelajaran sebesar 59,7308 dan rata-rata nilai post-test setelah diberikan treatment sebesar 82,115. Mahasiswa yang dinyatakan tuntas dengan $\mathrm{KKM} \geq 76$ setelah diberikan treatment sebanyak 20 mahasiswa (75,9\%) dan mahasiswa yang dinyatakan belum tuntas sebanyak 6 mahasiswa $(24,1 \%)$ sehingga disimpulkan proses pembelajaran berhasil.

Putri (2014) dalam penelitiannya yang berjudul "Pengaruh Pendidikan Kesehatan Gigi Dan Mulut Dengan Media Power Point Terhadap Tingkat Pengetahuan Siswa Usia 910 Tahun Di SD Negeri Keputran 2 Yogyakarta" memperoleh hasil $\mathrm{p}<0,05$ yang artinya terdapat perbedaan sebelum dan sesudah dilakukan pendidikan kesehatan gigi dan mulut dengan media PowerPoint. Hasil penelitian ini menyimpulkan bahwa terdapat pengaruh pendidikan kesehatan gigi dan mulut dengan media powerpointterhadap tingkat pengetahuan kesehatan gigi dan mulut siswa usia 9-10 tahun di SD Negeri Keputran 2 Yogyakarta.

Media powerpoint yang digunakan dalam penelitian ini adalah jenis media personalpresentation. Menurut Rusman, Kurniawan, dan Riyana (2013), jenis personalpresentation ini banyak digunakan dalam pembelajaran klasikal, dimana pembicara yang mengontrolnya proses pembelajaran. Media digunakan peneliti untuk membantu dalam menjelaskan materi tentang 
HIV/AIDS. Dalam media presentasi, yang ditampilkan hanya berbentuk teks dan gambargambar yang tidak bergerak.

Sunardi (2017) mengungkapkan bahwa media PowerPoint memiliki beberapa kelebihan, seperti: penyajian materi lebih menarik; merangsang peserta didik untuk mengetahui informasi tentang bahan ajar yang tersaji; pesan informasi yang disajikan mudah dipahami peserta didik; tidak perlu banyak menerangkan bahan ajar yang sedang disajikan; slide presentasi dapat diperbanyak sesuai kebutuhan, dan dapat dipakai secara berulang-ulang; serta dapat disimpan dalam bentuk data optik atau magnetik, sehingga praktis untuk dibawa ke mana-mana.Arsyad (2014) menjelaskan terdapat beberapa kelemahan dalam penggunaan media PowerPoint, antara lain: cukup menyita waktu dan tenaga untuk mempersiapkan dan para pendidik harus memiliki cukup kemampuan untuk mengoperasikan program ini.

Hasil penelitian terkait penggunaan media animasi menunjukkan ada perbedaan nilai mean antara sebelum dan sesudah pendidikan kesehatan sebesar 7,309 dengan standar deviasi 7,146. Uji statistik didapatkan p-value 0,000 maka dapat disimpulkan bahwa terdapat perbedaan yang signifikan antara pengetahuan responden sebelum dan sesudah diberikan pendidikan kesehatan dengan menggunakan media animasi.

Penelitian ini memiliki hasil yang sejalan dengan penelitian Tandilangi (2016) yang berjudul "Efektivitas Dental Health Education Dengan Media Animasi Kartun Terhadap Perubahan Perilaku Kesehatan Gigi Dan Mulut Siswa SD Advent 02 Sario Manado". Hasil uji statistik menunjukkan nilai $\mathrm{p}=0,000 \quad(<0,05)$ sehingga dapat disimpulkan bahwa dental health education dengan media animasi kartun efektif merubah perilaku pemeliharaan kesehatan gigi dan mulut menjadi lebih baik.

Penelitian Lingga (2015) juga mendukung hasil penelitian ini. Lingga (2015) meneliti tentang "Pengaruh Pemberian Media Animasi Terhadap Perubahan Pengetahuan Dan Sikap Gizi Seimbang Pada Siswa Kelas Vi Sekolah Dasar Negeri Tanjung Duren Utara 01 Pagi
Jakarta Barat". Hasil penelitian memperoleh rata-rata skor pengetahuan gizi seimbang sebelum pemberian media animasi adalah $36,90 \pm 4.22$, sedangkan rata-rata skor pengetahuan gizi seimbang sesudah pemberian media animasi adalah $39,28 \pm 4.76$. Hasil penelitian menunjukkan adanya pengaruh pemberian media animasi terhadap perubahan pengetahuan $(\mathrm{p}=0.003)$.

Lowe dalam Arsyad (2014) menemukan bahwa penerima informasi yang tidak memiliki pengetahuan awal akan cenderung memperhatikan perubahan animasi yang menarik secara perseptual dibandingkan dengan perubahan penting dalam memahami materi. Keefektifan media animasi juga dipengaruhi oleh perancangan atau pembuatan media animasi.

Media animasi terdiri dari kumpulan gambar atau objek yang diolah sedemikian rupa sehingga menghasilkan gerakan dari berbagai objek yang divariasikan dengan efekefek dan filter, gerakan transisi, suara-suara yang selaras dengan gerakan objek tersebut. Media animasi sebagai bentuk komunikasi yang dapat digunakan untuk menyampaikan informasi dari sumber ke peserta didik yang bertujuan merangsang mereka untuk mengikuti kegiatan pembelajaran (Asyhar, 2012). Animasi memiliki kemampuan untuk dapat memaparkan sesuatu yang rumit atau komplek atau sulit untuk dijelaskan dengan hanya gambar atau kata-kata saja, sehingga dapat digunakan untuk menjelaskan suatu materi yang secara nyata tidak dapat terlihat oleh mata, dengan cara melakukan visualisasi maka materi yang dijelaskan dapat tergambarkan (Asyhar, 2012).

Peneliti berpendapat bahwa pemberikan pendidikan kesehatan pada kelompok usia remaja harus menggunakan media pembelajaran yang kreatif dan inovatif sehingga dapat menstimulasi remaja untuk fokus dan memperhatikan materi yang disampaikan. Media animasi juga dapat mengurangi kesulitan dari pemberi materi (pendidik) dalam menjelaskan hal-hal yang abstrak dengan membuatkan visualisasi 
gambar bergerak dan bersuara serta menggunakan animasi kartun.

Hasil uji statistik didapatkan hasil p-value $0,005(\alpha 0,05)$, berarti ada perbedaan yang signifikan antara pengetahuan responden yang diberikan pendidikan kesehatan dengan menggunakan media powerpoint dan menggunakan media animasi. Berdasarkan hasil penelitian ini dapat disimpulkan bahwa penggunaan media animasi lebih efektif daripada media powerpoint dalam pemberian informasi tentang penyakit HIV/AIDS pada siswa/i SMK DB 1 Kota Jambi Tahun 2017.

Penelitian ini sejalan dengan penelitian Norazizah (2016) yang berjudul "Efektifitas Promosi Kesehatan Melalui Media Power Point Dan Video Terhadap Tingkat Pengetahuan Kader Tentang Kanker Serviks Di Wilayah Kerja Puskesmas Mlati I Program Studi Bidan Pendidik Jenjang Diploma Div Fakultas Ilmu Kesehatan Universitas 'Aisyiyah Yogyakarta". Hasilnya menunjukkan terjadi perubahan tingkat pengetahuan sebelum dan sesudah dilakukan promosi kesehatan, yaitu untuk media PowerPoint dari skor 12,90 dan meningkat menjadi skor 15,75. Sedangkan dengan media video sebelum dilakukan promosi kesehatan skor 13,80 dan menjadi skor 17,00 .

Penelitian lain, Priyani (2017) tentang Pengaruh Penyuluhan Media Powerpoint Dan Media Video Terhadap Tingkat Pengetahuan Ibu Tentang Kontrasepsi IUD Pasca Plasenta Di Puskesmas Kasihan I Bantul juga mendukung hasil penelitian yang peneliti lakukan. Hasil uji t-test diperoleh adanya perbedaan sebelum dan setelah dilakukan penyuluhan, dengan nilai $\mathrm{p}<0,05$ sehingga Ho ditolak $(0,020<0,05)$.

Penelitian media animasi yang peneliti gunakan dalam penelitian ini berbeda dengan media video, karena dalam media animasi menggunakan gambar-gambar animasi yang terdiri gambar kartun, bergerak, dan bersuara. Sedangkan media video umumnya menggunakan orang secara langsung yang berperan sesuai skenario yang telah dibuat.

Menurut peneliti, media animasi lebih unggul dalam meningkatkan pengetahuan remaja tentang HIV/ AIDS karena penyampaian materi lebih menarik dan dapat menstimulasi otak dari remaja untuk memahami materi yang diberikan secara lebih cepat. Sedangkan media PowerPoint yang digunakan dalam pendidikan kesehatan terkait HIV/AIDS kurang menarik perhatian dari remaja karena hanya berupa tulisan dan gambar.

\section{KESIMPULAN}

Kesimpulan yang dapat ditarik dari hasil penelitian ini adalah: ada perbedaan yang signifikan antara pengetahuan responden yang diberikan pendidikan kesehatan dengan menggunakan media powerpoint dan menggunakan media animasi( $p$-value 0,005 dan $\alpha 0,05)$. Hal ini berarti penggunaan media animasi lebih efektif daripada media powerpoint dalam pemberian informasi tentang penyakit HIV/AIDS.

Berdasarkan hasil penelitian ini maka disarankan dalam kegiatan promosi kesehatan pada remaja sebaiknya menggunakan media pembelajaran yang menggunakan gabungan antara tulisan, gambar bergerak, animasi, dan suara. Selain itu, diharapkan untuk melakukan penelitian pengembangan media pendidikan kesehatan yang lain dalam memberikan upaya preventif dan promotif pada remaja, khususnya terkait pencegahan HIV/AIDS.

\section{UCAPAN TERIMA KASIH}

Peneliti menyampaikan terima kasih dan pengharagaan kepada semua pihak yang telah membantu dalam proses penelitian ini, terutama Guru, Kepala sekolah dan Siswa/i SMK DB 1 Kota Jambi.

\section{DAFTAR PUSTAKA}

[1] Allender dan Spradley. Community Health Nursing: Concepts And Practice. Philadelphia: Lippincott; 2001

[2] Allender, Rector, dan Warner. Community Health Nursing: Promoting \& Protecting The Public's Health. Seventh Edition. Philadelphia: Lippincott William \& Wilkins; 2010 
[3] Andriany, Poppy. Perbandingan efektifitas media penyuluhan poster dan kartun animasi terhadap pengetahuan kesehatan gigi dan mulut pada siswa kelas V SDN 24 Kota Banda Aceh. Journal of Syiah Kuala Dentistry Society. 2016. 1: 63-72.

[4] Arsyad, A. Media Pembelajaran. Jakarta: Raja Grafindo Persada; 2014

[5] Asyhar, R. Kreatif MengembangkanMedia Pembelajaran. Jakarta:

Referensi; 2012

[6] Ditjen PP \& PL Kemenkes RI. Statistik Kasus HIV/ AIDS di Indonesia; 2014 [Diakses pada tanggal 17 Juli 2017] dari http://www.spritia.or.id

[7] Gareta, Sella Panduarsa. (2016). 38 Juta Orang Hidup Dengan HIV. Editor: Priyambodo RH. Diunduh dari http://www.antaranews.com pada tanggal 23 Juli 2017.

[8] General Asembly. Resolution adopted by the General Assembly on 25 September 2015. United Nations.

[9] Halimah, Wina. (2014). Pengaruh Media Power Point Terhadap Aktivitas Dan Penguasaan Konsep Siswa Di Smp AnNur Tulang Bawang Tengah Lampung. Skripsi. Fakultas keguruan dan ilmu pendidikan universitas lampung bandar lampung. [diakses pada tanggal 27 Oktober 2017] dari. http://download.portalgaruda.org

[10] Harahap, Syaiful W. Epidemi AIDS, Akankah Indonesia Bisa Jadi "Afrika Kedua"? [diakses pada tanggal 19 juli 2017] dari http://www.baranews.com

[11] Iradat, Damar.). Jumlah Kasus HIV \& AIDS di Indonesia Meningkat. [Diakses pada tanggal 17 Juli 2017] dari http://news.metro tvnews.com.

[12] Kemenkes RI. Laporan Perkembangan HIV-AIDS Triwulan I thn 2016. Jakarta: Dirjen Pencegahan dan Pengendalian Penyakit; 2016

[13] Lingga, Nurul Lolona. Pengaruh Pemberian Media Animasi Terhadap Perubahan Pengetahuan Dan Sikap Gizi Seimbang Pada Siswa Kelas Vi Sekolah
Dasar Negeri Tanjung Duren Utara 01 Pagi Jakarta Barat. Skripsi. Program Studi Ilmu Gizi Fakultas Ilmu-Ilmu Kesehatan Universitas Esa Unggul Jakarta. [Diakses pada tanggal 27 Oktober 2017] dari http:// digilib.esaunggul.ac.id

[14] Maryatun. (2015). Pengaruh Penggunaan Media Program Microsoft Powerpoint Terhadap Hasil Belajar Strategi Promosi Pemasaran Mahasiswa Semester 2 Program Studi Pendidikan Ekonomi Universitas Muhammadiyah Metro Tahun Ajaran 2014/2015. Jurnal Promosi: Jurnal Pendidikan Ekonomi UM Metro. ISSN: 2442-9449 Vol.3. No.1 (2015) 1-

13. Diunduh dari http://download.portalgaruda.org pada tanggal 27 Oktober 2017.

[15] Murni, S. (2011). Seri Buku Kecil "Hidup dengan HIV/AIDS. Jakarta: Yayasan Spiritia

[16] Norazizah, Rika. (2016). Efektifitas Promosi Kesehatan Melalui Media Power Point Dan Video Terhadap Tingkat Pengetahuan Kader Tentang Kanker Serviks Di Wilayah Kerja Puskesmas Mlati I Program Studi Bidan Pendidik Jenjang Diploma Div Fakultas Ilmu Kesehatan Universitas 'Aisyiyah Yogyakarta. Skripsi. Diunduh dari http://digilib. unisayogya.ac.id pada tanggal 27 Oktober 2017.

[17] Nurlailis. (2017). Waduh! Ada 1.537 Penderita HIV AIDS di Provinsi Jambi, Waspadai. Diunduh dari http://www.warta24.com pada tanggal 25 Juli 2017.

[18] Nursalam dan Kurniawati (2007). Asuhan Keperawatan Pada Pasien Terinfeksi HIV/ AIDS. Jakarta: Penerbit Salemba Medika.

[19] Priyani. (2015). Pengaruh Penyuluhan Media Powerpoint Dan Mediavideo Terhadap Tingkat Pengetahuan Ibu Tentang Kontrasepsi Iud Pasca Plasenta Di Puskesmas Kasihan I Bantul. Skripsi. Diunduh dari http://opac.say.ac.id pada tanggal 27 Oktober 2017. 
[20] Putri, Khanza Karina Ikhsan. (2014). Pengaruh Pendidikan Kesehatan Gigi Dan Mulut Dengan Media Power Point Terhadap Tingkat Pengetahuan Siswa Usia 9-10 Tahun Di Sd Negeri Keputran 2 Yogyakarta. Thesis. Program Studi Pendidikan Dokter Gigi Universitas Muhammadiyah Yogyakarta. Diunduh dari http://thesis.umy.ac.id pada tanggal 27 Oktober 2017.

[21] Pusat Data dan Informasi Kemenkes RI. (2014). Infodatin: Situasi dan Analsis HIV/ AIDS. Jakarta: Kemenkes RI.

[22] Rahman, Arpan. (2017). PBB: AIDS Renggut Satu Juta Jiwa Pada 2016. Diunduh dari http://www.international.metronews.com pada tanggal 23 Juli 2017.

[23] Rusman, Kurniawan, dan Riyana (2013). Pembelajaran Berbasis Teknologi Informasi dan Komunikasi: Mengembangkan profesionalitas Guru. Depok: Raja Grafindo Persada.
[24] Saputra, Ginto (2008). Pengetahuan, Sikap, dan Perilaku Berisiko HIV/AIDS Pada Siswa Kelas 3 SMA PGRI 1 Kota Bogor. Skripsi. Diunduh http://lib.ui.ac.id/ opac/themes/libri2/detail.jsp?id=124153$\underline{\text { S-5520 }}$ pada tanggal 23 Juli 2017.

[25] Stanhope, M., \& Lancaster, J. (2004). Community And Public Health Nursing. $5^{\text {th }}$ edition. St. Louis: Mosby-Year Book, Inc.

[26] Sunardi. (2017). Media Pembelajaran. Jawa Tengah: Kemenristek Dikti Kopertis Wilayah VI.

[27] Tandilangi, Meartriecs. (2016). Efektivitas Dental Health Education Dengan Media Animasi Kartun Terhadap Perubahan Perilaku Kesehatan Gigi Dan Mulut Siswa SD Advent 02 Sario Manado. Jurnal e-GiGi (eG), Volume 4 Nomor 2, Juli-Desember 2016. Diunduh dari pada tanggal 27 Oktober 2017. 